\title{
El nuevo sistema electoral a juicio. Definición en la voz de la Suprema Corte mexicana
}

\section{Víctor Collí Ek*}

\section{Sumario:}

I. Introducción

II. Los asuntos federales. El diseño general y marco

III. Asuntos de las entidades federativas

* Investigador en la Universidad Autónoma de Campeche. Actualmente responsable del proyecto de investigación: "La vigencia de la Constitución en la interpretación de la Suprema Corte de Justicia de la Nación como Tribunal Constitucional" 154998, financiado por el Conacyt a través del fondo para investigación científica básica, del cual el presente análisis, es un producto. 


\section{Introducción}

En los meses de septiembre y octubre de $2014,{ }^{1}$ el pleno de la Corte analizó la constitucionalidad de las nuevas leyes electorales, que se dieron como efecto de las reformas constitucionales, principalmente del 10 de febrero de $2014 .^{2}$ Se conocieron veintitrés asuntos, de donde surgió una visión integradora del funcionamiento del diseño electoral mexicano, sumamente complejo y enfáticamente interesante para su estudio.

Encontramos una miríada de temas, votos en el extranjero, segunda vuelta, tratamiento de equidad, las reservas de competencia para el Congreso de la Unión, funcionamiento del INE, la libertad de configuración de las entidades federativas, etcétera.

Las coaliciones serían definidas como una facultad del Congreso de la Unión, por eso en los casos locales, donde se contempló esto, se declaró inválido. Lo mismo es para el tema de financiamiento.

El gran tema fue la candidatura independiente, donde se reconoció la libertad de configuración de las legislaturas locales para definirla. En ese sentido se vieron temas como: no sustitución, porcentaje de registro, cancelación del registro, financiamiento equiparable a los partidos políticos de reciente creación, entre otros.

De igual manera se reconoció la libertad de configuración para las entidades federativas, en materia de votos en el extranjero.

El objetivo del presente análisis es rescatar las decisiones que fueron tomándose en las sesiones del pleno de la Corte mexicana y observar la viva emergencia del nuevo sistema electoral mexicano, inaugurado con las reformas constitucionales de 2014. Para darle orden a la exposición, trataremos los temas en dos grandes bloques: 1) asuntos federales, en donde se definió el diseño general y marco del sistema electoral; 2) asuntos de las entidades federativas ${ }^{3}$ en donde se asentó la libertad de configuración legislativa, en temas como candidaturas independientes, votos de los ciudadanos en el extranjero, entre otros.

1 Todas las sesiones de septiembre y del 1o. y 2 de octubre, de 2014.

2 En http://www.diputados.gob.mx/LeyesBiblio/ref/dof/CPEUM_ref_216_10feb14.pdf.

3 Es importante indicar que por la premura propia de la naturaleza y necesidad de resolución de estos casos, la exposición de los mismos en las sesiones públicas del pleno de la Corte, en varias ocasiones daba por obvios y conocidos datos, que desde la vista de un espectador no lo son así, algunos de ellos no pudieron reconstruirse, por lo que en ocasiones, únicamente se enuncia el problema planteado. 
Es importante indicar, que por el número de asuntos, la complejidad y novedad del tema, al igual que el espacio, nos referimos a los aspectos más fundamentales de lo discutido.

\section{Los asuntos federales. El diseño general y marco}

El primer asunto resuelto ${ }^{4}$ en el tema electoral en septiembre, es sin duda, el más complejo, en él, por la competencia de las leyes impugnadas, se definirá sustancialmente el diseño del sistema electoral en México, implementado por las reformas constitucionales, como veremos a continuación.

\section{Coaliciones}

En la primera parte de este tema, la Corte analizaría cuál es el marco constitucional y legal para las "coaliciones". Llegaría a la conclusión de que, las legislaturas de los Estados no tienen competencia para legislar sobre ellas, esto es competencia federal, en virtud de que se persigue la conformación de un sistema uniforme, que será regido mediante una ley general. ${ }^{5}$

En la segunda parte, ${ }^{6}$ el problema central radicaba en el tema de coaliciones, ¿cómo se va realizar el escrutinio y cómputo y cómo van a valer los votos?, ¿se tomarán en cuenta para la representación proporcional?

La hipótesis era que:

Al marcarse en la boleta electoral dos o más opciones de los partidos coaligados, si bien se tiene conocimiento de la preferencia del elector por el candidato postulado por la coalición para efectos de mayoría relativa, no se sabe a ciencia cierta, a qué partido político quiso favorecer con su voto, para efectos

4 Acción de inconstitucionalidad 22/2014 y sus acumuladas 26, 28 y 30/2014. Ponente ministra Margarita Luna Ramos, sesionada los días 1o., 2, 4, 8 y 9 de septiembre. Se analizaron diversas disposiciones de: Ley General de Instituciones y Procedimientos Electorales (LGIPE), Ley General de Partidos Políticos (LGPP), Ley General del Sistema de Medios de Impugnación en Materia Electoral (LGSMIME) y la Ley Orgánica del Poder Judicial de la Federación (LOPJF).

5 Mayoría de 9 votos, sesión del 8 de septiembre, p. 56.

6 Mayoría de 9 votos, sesión del 8 de septiembre, p. 71. 
de representación proporcional, dificultando la asignación de curules por este principio, ante lo cual el legislador decidió no tomar en cuenta el voto para tales efectos.

Lo anterior se consideró inconstitucional por varias razones. No se pueden prever condicionantes adicionales a las que establece la Constitución mexicana (CPEUM), para la asignación de representación proporcional, con el efecto de afectar la integración de las cámaras del Congreso y distorsionar la voluntad del elector. La CPEUM determina que todo partido político que cumpla con los requisitos ahí planteados, tiene derecho a la asignación de diputados y senadores por representación proporcional, sin hacer referencia a la hipótesis arriba planteada.

Igualmente, se limitaba el efecto del voto del ciudadano, a quien solo se le estaría tomando en cuenta su voto, para la elección de candidatos por mayoría relativa, no así por el de representación proporcional, violentando el principio de consideración igualitaria del voto.

Por otro lado, se afectaban las prerrogativas en materia de financiamiento público y acceso a los medios de comunicación, las cuales se otorgan, una parte, del porcentaje de votos obtenidos en la elección de diputados inmediata anterior.

Además, dañaba de manera desproporcionada a los partidos políticos, dependiendo del grado de representación, todo esto, afectando un principio de equidad, de representación electoral y reducción injustificada del acceso a listas de representación proporcional.

\section{Candidaturas independientes}

Este tema será el más analizado de todos y tendrá un impacto en el diseño federativo, por lo que se retomará en los asuntos de las entidades federativas.

A. Inequidad de los plazos de registro de los aspirantes a candidatos independientes, frente a lo establecido para la creación de nuevos partidos políticos ${ }^{7}$

No existe tal inequidad diría la Corte, ya que constituyen dos formas diferentes de promoción política. En el caso de partidos, no se trata de difundir las cualidades de un individuo frente a potenciales electores,

\footnotetext{
7 Unanimidad, sesión del 4 de septiembre, p. 60.
} 
sino ofrecer una nueva opción ideológica en sentido político, a la cual podría adherirse la ciudadanía. En el caso de candidatos independientes, la pretensión es postularse como candidato sin partido, alguien que busca el respaldo ciudadano.

\section{B. Porcentaje de respaldo ciudadano para que las candidaturas independientes obtengan su registro ${ }^{8}$}

La CPEUM no estableció un valor porcentual para que las candidaturas independientes demostraran el respaldo ciudadano para poder postularse, esto quedó al margen del legislador secundario, el cual tiene la facultad para configurar: la forma de acreditar el apoyo ciudadano para el registro, y las cifras suficientes con que se debe demostrar documentalmente el apoyo.

De igual forma, los plazos para recabar el respaldo ciudadano de los candidatos independientes es diferente al de los partidos políticos, por lo que la diferencia no puede ser motivo de afectación a la igualdad. En el primero, se promueve el apoyo para registrar a una persona, mientras que en el segundo, se hace proselitismo a favor de una ideología política para conformar un nuevo partido político, cuyos candidatos en concreto aún no se conocen.

\section{Requisitos para el registro de las candidaturas independientes ${ }^{9}$}

Primeramente, no se consideró que exista una "sobrerregulación" en cuanto a las exigencias de que los aspirantes a candidatos independientes demuestren ser ciudadanos mexicanos en pleno ejercicio de sus derechos políticos, mediante su acta de nacimiento y credencial para votar vigente, estos son documentos mínimos para crear los requisitos básicos de elegibilidad - nacionalidad mexicana y titularidad plena de la prerrogativa ciudadana-.

Por otro lado, la solicitud de los datos de la cuenta bancaria en la que se concentra la actividad financiera de la candidatura independiente, no es un requisito de elegibilidad, sino un mecanismo de control financiero

8 CPEUM, artículos 35, fracción II, 41 y 116, segundo transitorio del decreto de reforma constitucional. Unanimidad, sesión del 4 de septiembre, p. 63.

9 LGIPE, artículos 384, 385, 386. CPEUM, artículos 14 y 41. Unanimidad de votos, con excepción de lo relativo al artículo 385, párrafo 2, incisos $b$ y $g$ de la LGIPE, donde hay ocho votos. Sesión del 4 de septiembre, p. 69. 
de ingresos y egresos, cuyo fin es permitir vigilar el origen de los recursos y su correcta aplicación.

De igual forma, no se consideró incorrecto que se reconozca solo la primera manifestación de un ciudadano a favor de un aspirante a candidato independiente, cuando haya existido más de una, ya que no se trata de una filiación permanente, sino un mero respaldo coyuntural, que no coloca al ciudadano que lo formula, en calidad de militante.

D. Obligación de entregar informes financieros de los actos tendentes a recabar el respaldo ciudadano ${ }^{10}$

Se resolvió que la obligación de entregar los informes financieros del proceso, para recabar el apoyo ciudadano por parte de aspirantes a candidatos independientes, so pena de negar el registro o imponer sanciones procedentes, es la única medida coactiva para hacer efectiva esta obligación y con ello poder verificar el origen y destino lícito de los recursos económicos. En ese sentido, no tiene el objetivo o efecto de disuadir a los aspirantes, a participar en el ejercicio del derecho fundamental de los ciudadanos a postularse a un cargo de elección popular en forma independiente.

\section{E. Sanciones fijas y negativa o privación de registro por actos anticipados de campaña y uso indebido de la radio y televisión ${ }^{11}$}

Se argumentaba que plantear como única sanción la de perder el registro, negativa o cancelación del registro para los candidatos independientes, en los supuestos de actos anticipados de campaña durante el periodo de obtención del respaldo ciudadano, contratar propaganda en radio y televisión y rebasar los topes de gastos de campaña, resultaba una medida desproporcional por considerarse multa fija excesiva.

La Corte, cambiando el sentido original en el que se presentó el proyecto, decidiría que no pueden aplicarse los precedentes sobre el tema de multa fija (artículo 22, CPEUM) porque se estaría comparando partidos políticos-candidatos independientes, en la base de ser iguales y no es así, más bien la comparación es entre desiguales. Adicionalmente, declarar que el supuesto es inconstitucional — una multa fija - dejaría imposibili-

10 Unanimidad de votos. Sesión del 4 de septiembre, p. 73

11 LGIPE, artículos 327, párrafos 1 y 2; 375, párrafo 1. CPEUM, artículo 22. Unanimidad de votos por la propuesta modificada, sesión del 4 de septiembre, p. 82 . 
tada a la autoridad de sancionar a los candidatos independientes, pues al expulsar la norma, no habría alguna otra para ejercer tal facultad.

\section{F. Financiamiento público para las candidaturas independientes en su conjunto como si fueran un partido de nueva creación ${ }^{12}$}

El establecimiento del financiamiento público para las candidaturas independientes en estos términos, no imprime un criterio de inequidad por parte de la ley secundaria, ya que esto se debe a un mandato expreso de la CPEUM. Argumenta la Corte que los candidatos independientes no pueden ser considerados equivalentes a los partidos políticos, por las características propias de cada uno, los candidatos no pretenden adquirir la permanencia de un partido, al igual que este último importa una regla general de ser el fin específico de integrar la representación nacional para acceder al poder, mientras que los candidatos independientes son la excepción. El propósito del Constituyente, señalaría la Corte, es animar la creación de partidos políticos y no la de candidatos sin ellos, como se aprecia de su diverso mandato de fraccionar entre estos últimos los tiempos de radio y televisión, como si fuera un solo partido.

\section{G. Prohibición para las candidaturas independientes para recibir dinero en efectivo, así como metales y piedras preciosas ${ }^{13}$}

No se trata de la misma manera a los partidos políticos y a los candidatos independientes, en la regla de la prohibición de recibir aportaciones y donaciones en efectivo, así como metales y piedras preciosas, de cualquier persona moral o física.

Mientras a los partidos políticos se les permite, siempre que la persona física sea identificable, mediante cheque o transferencia bancaria y con factura respectiva, a los candidatos independientes, se les prohíbe totalmente, pero esta diferencia se da justamente porque partidos políticos y candidatos independientes, son categorías distintas y la prohibición concreta tiene razonabilidad.

12 Votación económica, sesión del 4 de septiembre, p. 90.

13 Votación económica, sesión del 4 de septiembre, p. 95. 
H. Prohibición para substituir a los propietarios de las fórmulas de diputados o senadores postulados como candidatos independientes ${ }^{14}$

La Corte resolvería que tanto los candidatos independientes registrados individualmente para el cargo de diputados, como en alguna de las dos fórmulas para la elección de senadores, en ambos casos de mayoría relativa, son insustituibles por sus suplentes, mientras que no triunfen en la elección, ya que el derecho a ser registrados como candidatos independientes, lo hacen a título personal.

\section{Prohibición para las candidaturas independientes de recibir aportaciones o donativos de empresas mercantiles ${ }^{15}$}

Se argumentaba que las empresas no podían dar este tipo de donativos, cosas que otras personas morales sí podían hacer, lo cual generaba una inconsistencia legislativa. Esto, diría la Corte, no es así, porque si se analiza el marco jurídico, se observará que existen otro tipo de prohibiciones para otro tipo de personas morales. Igualmente, se subraya que existen este tipo de prohibiciones para los partidos políticos.

\section{J. Trato desigual a las candidaturas independientes ${ }^{16}$}

Se argumentaba que se exigían mayores requisitos para las candidaturas independientes, que para los partidos políticos, lo que se consideraba contrario a los tratados internacionales.

La Corte resolvería que no hay violación alguna, retoma la jurisprudencia de la Corte Interamericana de Derechos Humanos en el caso Castañeda, e indica que ahí la Corte internacional en ningún momento se refirió al trato idéntico a los candidatos independientes y a los partidos políticos, autorizando la existencia de un trato normativo diferenciado.

14 LGIPE, artículo 392.Votación económica, sesión del 8 de septiembre, p. 5.

15 LGIPE, artículo 401, párrafo 1, inciso $i$. Votación económica, sesión del 8 de septiembre de 2014, p. 6.

16 LGIPE, artículos 357-439. 


\section{Derecho de asociación política}
A. Establecimiento estatutario de categorías de afiliados a los partidos políticos ${ }^{17}$

Se argumentaba que permitir a los partidos políticos establecer diversas categorías de sus militantes, de acuerdo con su clase, condición social o personal, afectaba el principio de igualdad, resulta discriminatorio, $y$ afectaba el principio de pleno derecho de asociación política.

Las categorías a las que se aludía, solo están refiriéndose al grado de compromiso que adquieren los afiliados en un partido. Por ejemplo, militantes con obligaciones inherentes a esa responsabilidad, como el pago de cuotas, mientras que por otro lado puede haber personas que pertenezcan a la organización política, pero no aporten apoyo económico de manera permanente $\mathrm{u}$ otra forma de participación continua.

En ese sentido, no hay violación del principio de igualdad, porque la diferencia se refiere al grado de compromiso de una persona en relación con el partido político, ya que se genera una relación responsabilidad-deberes-obligaciones, que no hacen referencia a la calidad de las personas.

\section{B. Exclusión del Distrito Federal para poder establecer otras formas de participación o asociación de los partidos políticos con el fin de postular candidatos ${ }^{18}$}

Se argumentaba que para la ley, al hacer referencia a las "Constituciones locales" como parámetro normativo, para establecer otras formas de participación o asociación de los partidos políticos, con el fin de postular candidatos, estaba excluyendo al Distrito Federal.

La ministra ponente prepararía dos propuestas. La segunda sería la vencedora, aquella en la que la Corte utiliza precedentes, donde se determinó que a pesar de que el Distrito Federal no tiene una Constitución, el Estatuto de Gobierno es prácticamente su Constitución y como tiene su fundamento en el artículo 122 de la CPEUM, el precedente señala que se integra un "bloque de constitucionalidad en materia electoral".

17 LGPP, artículo 40. CPEUM, artículos 1o., párrafo primero; 41, fracción I, párrafo segundo; 70, párrafo tercero; artículos 99, fracción V, y 116, fracción IV. Unanimidad, sesión del 4 de septiembre, p. 47.

18 LGPP, artículo 85, párrafo 5. CPEUM, artículos 1o., 7o., 9o, 14, 16, 35, 40, 41, 116, fracción IV, 122 y 133. Unanimidad, sesión del 4 de septiembre, p. 54. 


\section{Propaganda electoral ${ }^{19}$}

¿Es constitucional la difusión de informes anuales gubernamentales rendidos fuera de los periodos de campaña? ${ }^{20}$

La CPEUM es omisa sobre lo que se debe considerar propaganda electoral en esta dimensión - afirmaría la Corte-, porque se encuentra pendiente la emisión de la ley reglamentaria respectiva, en ese sentido, la ley electoral en análisis está fungiendo como norma supletoria. ${ }^{21}$

No se considera propaganda porque: primeramente está referida no solo a la promoción política personal, sino a la rendición de cuentas, al igual que es de carácter informativo e institucional. De la misma forma se dan parámetros que deben cumplirse, a fin de que no sirva de proselitismo: realizarse anualmente para efectos del informe, cobertura regional limitada, que no exceda de seis días antes y cinco días después del informe y que el contenido no pueda considerarse como prohibido legalmente.

\section{Partidos políticos ${ }^{22}$}

Lo primero que se argumentaba es que al determinarse que los partidos políticos deberán tener cuando menos una serie definida de órganos internos, ${ }^{23}$ se estaba interfiriendo indebidamente con la vida interna de los mismos.

La Corte resolvería que el marco normativo manda a la existencia, de cuando menos una serie de órganos internos, con características definidas, pero que no impide la creación de otros órganos diversos a los indicados, siempre que se establezcan, por ejemplo, el número de integrantes en cada caso, la duración en el cargo, atribuciones en específico.

19 LGIPE, artículo 242, párrafo 5. CPEUM, 134 párrafo 8. Se relaciona con las acciones de inconstitucionalidad 131/2008, consultable en http://www2.scjn.gob.mx/ConsultaTe matica/PaginasPub/DetallePub.aspx?AsuntoID=104985 y 129/2008, consultable en http:// www2.scjn.gob. $m x /$ Con sultaTematica/PaginasPub/DetallePub.aspx?AsuntoID $=104930$.

20 Unanimidad, sesión del 1o. de septiembre, p. 55.

${ }_{21}$ Cfr. http://fundar.org. $m x / s c j n$-recuerda-al-legislativo-que-tiene-pendiente-regular-la -publicidad-oficial/\#.VPS2RFOG8mU.

22 Acción de inconstitucionalidad 23/2014 y sus acumuladas. Sesionada los días 8 y 9 de septiembre de 2014. Ponente ministro Sergio Valls Hernández.

23 LGPP, artículo 43. Votación económica, sesión del 8 de septiembre, p. 85. 
Por otro lado, se consideraba excesivo que la norma ${ }^{24}$ impusiera reglamentos mínimos, que deben regir los procedimientos de democracia intrapartidista, para la conformación de candidatos de elección popular, tales como: convocatoria, reglas claras del proceso de selección y registros de precandidatos y candidatos, etcétera.

Se resolvería que no es excesivo, más bien se considera un límite razonable a la autoorganización y autorregulación de los partidos, ya que son reglas básicas que llevan a la democracia intrapartidista, y permiten desarrollar a libertad el contenido de las mismas.

Se afirmaba que no es razonable que se exija el establecimiento de procedimientos de justicia intrapartidaria, que incluyan mecanismos alternativos de solución de controversias, reglas básicas de integración y funcionamiento del órgano responsable de impartir justicia interna, al igual que garantías mínimas en el desarrollo de los procedimientos respectivos. ${ }^{25}$

Es razonable, afirmaría la Corte, primero porque reduce la necesidad de intervención del Estado a través de sus órganos electorales y permite al partido contar con un completo y eficiente sistema de justicia partidaria. Segundo, garantiza el debido proceso en los diferentes medios de justicia intrapartidaria, salvaguardando al mismo tiempo, los derechos de los militantes y el cumplimiento de los fines constitucionales. En resumen, se fortalece la autonomía de los partidos.

\section{Delitos electorales ${ }^{26}$}

El problema radicaba en que se eliminó como conducta a sancionar la "orientación" del sentido del voto - solo se dejaron como conductas punibles, la presión o inducción - esto permite, de acuerdo a los demandantes, que los ministros de culto puedan inmiscuirse en asuntos político electorales y proselitistas.

La Corte declararía que la eliminación de la "orientación" del sentido del voto por parte de ministros religiosos, como conducta que genera un

24 LGPP, artículo 44. Votación económica, sesión del 8 de septiembre, p. 87.

25 LGPP, artículos 46, 47 y 48. Unanimidad por los artículos 47 y 48 . Mayoría de 7 votos por el artículo 46. Sesión del 8 de septiembre, p. 93.

26 Acción de Inconstitucionalidad 50/2014. Ley General en Materia de Delitos Electorales, artículo 16. CPEUM, artículo 24. Ponente ministro Alberto Pérez Dayán. Sesión del 8 de septiembre. Mayoría de ocho votos, p. 111. 
delito, se encuentra dentro de las facultades del legislador y su libertad de configuración legislativa, por lo que la norma es adecuada.

\section{Asuntos de las entidades federativas}

\section{Derechos humanos. Los temas}

Posible restricción injustificada a la libertad de expresión, por límites adicionales a los establecidos en la CPEUM, al deber de abstenerse de denigrar a las instituciones, a otros partidos. Afirmaría que constitucionalmente solo se protege a las personas frente a la propaganda política o electoral que las calumnie, pero no a las expresiones que las denigre en ese sentido, la medida no tiene cabida dentro de las limitaciones expresas en el 6o. constitucional. ${ }^{27}$

Restricción injustificada y arbitraria del derecho al voto como elector, por diversas categorías sospechosas, como impedir ser elector a la persona que esté sujeta a un proceso penal, por delito que merezca pena privativa de libertad, desde que se dicte el auto de formal prisión. La Corte decidiría hacer una interpretación conforme, en el sentido de que se diera el impedimento, solo tratándose de personas privadas efectivamente de su libertad, y no de aquellas que aún con un auto de formal prisión, se encuentren gozando de su libertad. ${ }^{28}$

Igualmente, decidió que no es aceptable excluir como electores a las personas con discapacidad y aquéllas con enfermedades mentales, ya que la norma impugnada se aparta de los compromisos internacionales, principalmente de la Convención sobre los Derechos de las Personas con Discapacidad.

Tampoco es aceptable excluir a los "ebrios consuetudinarios" y a las personas toxicómanas, ambos "fármaco-dependientes", la Corte haría un estudio detallado del carácter histórico, teleológico, integral y competencial de la CPEUM, los precedentes jurisprudenciales y diversos tratados de derechos humanos y de fiscalización de drogas, para sostener que actualmente no es posible excluir a las personas por condición de salud. ${ }^{29}$

27 Sesión del 2 de octubre, p. 111.

28 Sesión del 2 de octubre de 2014, p. 158.

29 Sesión del 2 de octubre de 2014, p. 160. 


\section{Candidaturas comunes. Sobre ello se estudió...}

\section{A. Falta de sustento constitucional}

Se argumentaba que esta figura carecía de ello. La Corte contestaría que esta determinación cae dentro de la libertad de configuración legislativa local, la cual puede establecer las formas de intervención de los partidos políticos en los procesos electorales, lo que puede definirse en la ley ordinaria o la Constitución local. ${ }^{30}$

\section{B. Prohibición de candidatura común por nuevo registro}

Otro argumento que encontramos, es la prohibición para los partidos de nuevo registro, de participar en una candidatura común, bajo el argumento de que violentaban los derechos de asociación, participación política, al igual que el derecho de ser votado a cargos de elección popular. ${ }^{31}$

La Corte resolvería que esto no es así, la disposición es razonable. Atendiendo a los principios constitucionales, se requiere que los partidos nuevos demuestren ser una verdadera opción para los ciudadanos y para tal fin, es necesario que en la primera contienda electoral, participen de manera individual.

3. Candidatos independientes. De esta figura se analizó...

\section{A. Limitación del número}

Se limitaba el registro de candidatos independientes, solo a aquel que lograra el mayor apoyo, el ponente propuso declarar inconstitucional la medida, lo que no alcanzó mayoría. ${ }^{32}$

\section{B. Responsabilidad por recibir aportaciones}

Una causa refrendada por la Corte, para incurrir en responsabilidad por parte de los aspirantes y los propios candidatos independientes, es la de

30 Mayoría de 9 votos, sesión del 22 de septiembre, p. 97.

31 Encontramos los siguientes asuntos: (4) Unanimidad de 10 votos, sesión del 9 de septiembre, p. 23; (7) Mayoría de 8 votos, sesión del 22 de septiembre, p. 114; (10) Unanimidad de 8 votos, sesión del 25 de septiembre, p. 69.

32 Empate a 5 votos, por lo que se desestimó, sesión del 30 de septiembre, p. 34 . 
recibir aportaciones en efectivo, metales o piedras preciosas, ${ }^{33}$ lo que llevó igualmente a definir que no puede establecerse una comparación entre éstos y los partidos políticos, pues las candidaturas no mantienen la permanencia que permite su fiscalización por parte de la autoridad. ${ }^{34}$

\section{Relación con partidos políticos}

Resulta aceptable, resolvería la Corte, para el derecho de ser votado, el que no puedan ser candidatos independientes, quienes hayan tenido algún cargo de dirigencia en algún partido político. El tiempo previo varía dependiendo de la legislación local: un año, ${ }^{35}$ dos años $^{36}$ o tres años. ${ }^{37}$

\section{Requisitos para el registro}

El marco normativo se argumentaba inválido porque no guardaba proporcionalidad y razonabilidad con los términos constitucionales, en específico la obligación de entregar: constancia de inscripción al padrón electoral, constancia de entrega de informes de gastos y egresos de los actos tendientes a obtener el apoyo ciudadano y la copia simple, por ambos lados, de la credencial para votar.

Primero, definiría la Corte que esto se encuentra dentro de la libertad de configuración de las legislaturas estatales. Además, de acuerdo con sus razonamientos, los anteriores se consideraron documentos idóneos para acreditar la exigencia de demostrar ser ciudadano mexicano en pleno ejercicio de sus derechos políticos, para los aspirantes a candidatos independientes, el acta de nacimiento, la credencial para votar vigente y la constancia de inscripción en el padrón electoral.

\section{E. Respaldo ciudadano}

Resolvería como constitucional, que se le imponga a los ciudadanos que decidan manifestar su respaldo a algún aspirante a candidato independiente, presentar copia de su credencial para votar, ya que se considera

33 Votación favorable, sesión del 23 de septiembre de 2014, p. 98; votación favorable, sesión del 23 de septiembre, p. 98; votación favorable, sesión del 30 de septiembre, p. 82.

34 Votación favorable, sesión del 30 de septiembre, p. 80.

35 Mayoría de 7 votos, sesión del 25 de septiembre, p. 8.

36 Mayoría de 6 votos, sesión del 25 de septiembre, p. 66.

37 Mayoría de 8 votos, sesión del 29 de septiembre, p. 17. 
un requisito razonable para demostrar cuál de los aspirantes obtuvo un mayor número de respaldos, y por tanto cumple con los requisitos de elegibilidad. ${ }^{38}$

\section{F. Licitud de los recursos}

Definió válido que quienes hayan obtenido el derecho a contender como candidatos independientes, al momento de solicitar su registro, deban entregar el dictamen en el que el Instituto Electoral hubiere confirmado la licitud del origen y destino de los recursos. ${ }^{39}$ Lo anterior permitirá verificar y controlar los recursos por parte de la autoridad electoral. ${ }^{40}$

\section{G. Plazos para respaldo ciudadano}

Fijar los plazos para la obtención del respaldo ciudadano ${ }^{41}$ es constitucional, ya que se trata de una fase más dentro de un procedimiento complejo en la selección de candidatos independientes, por lo que debe tener un plazo perentorio que permita el desarrollo de dicho procedimiento y sus diversas etapas. Al igual que está inmerso en el proceso electoral, por lo que el plazo debe estar limitado y permitir garantizar el derecho de votar y ser votado.

Los plazos de cuarenta y treinta días, respectivamente, se consideraron idóneos y suficientes para la obtención del respaldo ciudadano, lo que garantiza el derecho de votar y ser votado. ${ }^{42}$

Además, se resolvió que no es inadecuado que estos plazos varíen dependiendo del cargo al que se quiera aspirar, se estiman razonables, en tanto posibilitan el ejercicio del derecho de los ciudadanos a ser registrados como candidatos independientes. ${ }^{43}$

38 Unanimidad de 9 votos, sesión del 25 de septiembre, p. 12; votación favorable. Sesión del 29 de septiembre, p. 18; unanimidad de votos, sesión del 30 de septiembre, p. 73. Precedentes en las A.I. 33 y 42/2014.

39 Votación favorable, sesión del 25 de septiembre, p. 13.

40 Votación favorable, sesión del 22 de septiembre, p. 47.

41 Votación favorable, sesión del 25 de septiembre, p. 14. Temas similares con la acción de inconstitucionalidad 32/2014 (14) LIPEG, artículo 298. Votación favorable, sesión de 30 de septiembre, p. 62.

42 Votación favorable, sesión del 30 de septiembre, p. 17.

43 Votación favorable, sesión del 22 de septiembre, p. 42. 


\section{H. Conteo del respaldo ciudadano}

Se analizaba la forma de computar las manifestaciones de respaldo de los aspirantes a candidatos ciudadanos. Señalaría la Corte, en primer lugar, que existe una amplia libertad de configuración de las entidades federativas, para establecer requisitos variados y diferenciados, además de que es un medio adecuado para acreditar certeramente, el suficiente respaldo ciudadano, necesario para participar como candidato independiente. ${ }^{44}$

El porcentaje se encuentra relacionado con el número de manifestaciones de apoyo que requiere cada aspirante para ser registrado como candidato independiente. Además, el hecho de que al gobernador se le exija un mayor porcentaje, es solo consecuencia de que la lista de la elección es mayor porque abarca la totalidad del Estado. ${ }^{45}$ Depende del puesto de elección popular relativo, resulta proporcional y congruente, se relaciona con la demarcación territorial que corresponde

\section{Financiamiento}

Las personas que hayan logrado el registro de candidato independiente tendrán derecho a recibir financiamiento público. Esta decisión es parte de la libertad de configuración de las entidades federativas (en vista de que la CPEUM no tiene indicación específica) las cuales pueden equiparar a estas figuras, con los partidos políticos que reciban menor financiamiento. ${ }^{46}$

\section{Mexicanos en el extranjero. Los temas}

Es facultad de la legislatura local, regular lo relativo a votaciones de los michoacanos en el extranjero. ${ }^{47}$

La Constitución local limitaba el voto en el extranjero a las elecciones de gobernador, lo que se argumentaba violaba el derecho de voto. Se re-

44 Mayoría de seis votos, sesión del 25 de septiembre, p. 18. Mayoría de 9 votos, sesión del 30 de septiembre, p. 24. Mayoría de 9 votos. Ibidem, p. 20.

45 Mayoría de 8 votos, sesión del 25 de septiembre, p. 21. Temas similares con la acción de inconstitucionalidad 32/2014.

46 Votación favorable, sesión del 25 de septiembre, p. 29. Relacionado con la acción de inconstitucionalidad 22 y 32/2014 (6) CEEC: 355. Votación favorable, sesión del 22 de septiembre, p. 74.

47 Mayoría de 8 votos, sesión del 23 de septiembre, p. 98. 
solvería que esta materia se encuentra dentro de la libertad de configuración del legislador local, y mientras no contravengan lo establecido en la CPEUM, es válido. ${ }^{48}$

Un tema sin precedente, el candidato migrante o binacional. ${ }^{49} \mathrm{Se}$ argumentaba que la figura no tiene una representación proporcional o territorial efectiva. La Corte resolvería que este legislador representa a los guerrerenses que están fuera del Estado, pero han ido contribuyendo con el Estado en diversos ámbitos.

Al contar con una residencia binacional, conoce los intereses de sus representados, y los defiende en el interior del poder público del que forma parte. La unidad territorial que le corresponde tiene el espacio donde se asienta la comunidad a la que representa, y aquél donde desarrolla sus labores. ${ }^{50}$

48 Mayoría de 8 votos, sesión del 30 de septiembre, pp. 60 y 61.

49 Legislación del Estado de Guerrero.

50 Votación favorable. Sesión del 25 de septiembre, p. 61. 